\title{
A Comparative Study for Weldability Prediction of AHSS Stackups
}

\author{
Huu Tan Tran ${ }^{1}$, Hyung Jeong Yang ${ }^{1}$, Kyoung-Yun Kim ${ }^{2}$ and Raj Sohmshetty ${ }^{3}$ \\ Department of Electronics and Computer Engineering, Chonnam National \\ University, Gwangju 500-757, Republic of Korea \\ Department of Industrial and Systems Engineering, Wayne State University, \\ Detroit, MI 48202, USA \\ Ford Motor Company, Dearborn, MI 48124, USA \\ fami.hut89@gmail.com,hjyang@jnu.ac.kr,kykim@eng.wayne.edu, \\ rsohmshe@ford.com
}

\begin{abstract}
Resistance welding is the most commonly implemented method to join steel sheets in the automobile industry. To increase the efficiency and to maintain or reduce the weight of vehicles, advanced high-strength steel (AHSS) has been developed as a build material for vehicular structures. This paper aims to exploit the ability of prediction for nugget sizes in resistance spot welding by using support vector regression (SVR) and artificial neural network (ANN) model. In this study, the nugget size will be predicted according to parameters in resistance spot welding, such as welding current, welding time and welding force, etc. using machine learning methods. In addition to considering important process parameters for resistance spot welding, some design parameters, such as the thickness of the materials and the coating, are also considered. As the experimental results, SVR shows better performance in the prediction of nugget size when compared to ANN.
\end{abstract}

Keywords: Resistance Spot Welding, Support Vector Regression, Artificial Neural Network, Weldability Prediction, Advanced High Strength Steels

\section{Introduction}

Nowadays, new and advanced materials, such as advanced high-strength steel (AHSS), have been continuously evolving, allowing automobile manufacturers to create products that meet high performance requirements while reducing the weight of products. Due to the competitiveness in the automotive industry, automobile manufacturers want to develop design-decision support tools based on machine learning techniques, which can help to achieve engineering efficiency, cost, and product quality improvements when using new materials (e.g., AHSS or high-strength low-alloy steel) [1]. Prediction is one of tasks that use machine learning techniques to evaluate weldability in resistance spot welding, a core joining method in the automobile manufacturing.

Advanced high-strength steel (AHSS) has been investigated by researchers and manufacturers since AHSS is an alternative material that can be used for the body structure of commercial vehicles (e.g., car, train, ship, aircraft, etc.). When compared to mild steels, AHSS presents some significant advantages in weight reduction without compromising the safety of the passengers or the durability of the vehicle. These advantages enable retrenchment of fuel consumption and reduction of hazardous emissions. Furthermore, AHSS sheet materials have a relatively low cost and demonstrate higher strength and better results in crash tests [2]. Hence, an AHSS material is considered to be a viable alternative as structural components in automobiles. 
A material's weldability is used to identify the proper welding process and to compare the final weld quality against that of other materials. In resistance spot welding (RSW), weldability assessment is a very important task. It helps manufacturers to evaluate weld quality, so that they can propose more efficient strategies for the welding process. Many methods for weldability assessment have been proposed [3-4]. Finite element analysis is a numerical technique that aims to obtain approximated solutions to boundary value problems by using differential equations. This method uses variation methods to minimize an error function and to create a stable solution [5]. However, the multi-physical nature of RSW often hinders realistic finite element analysis. A RSW process should be understood by incorporating structural and thermal aspects and often by also including fluid dynamics. Another challenge for finite element analysis is that the high-temperature material properties are often not available, unlike those at room temperature. Another approach is a rather statistical approach, which is the Taguchi method [6]. This method has been exploited for design optimization of resistance spot welding, inheriting the challenges of the dynamic process.

Machine learning methods are considered for an alternative method that uses actual welding test data for weldability prediction. Machine learning methods have many advantages, including that they are flexible and efficient when performing non-destructive quality estimation during the assessment process. There are many machine learning techniques that have been proposed by researchers for forecasting, such as artificial neural networks [3, 7-8] and support vector regression [9-11]. Support vector regression (SVR) is extended to make predictions from Support vector machines (SVM) which are flexible methods that work with nonlinear models, even though all data do not present the same functional form and the function is non-parametric and operates locally [12]. Support Vector Regression (SVR) is extended from SVM to make predictions with the foundation of Vapnik's $\varepsilon$-insensitive loss function [13]. This method has been applied in many fields and has shown good results (e.g., prediction of tacrolimus blood concentration [9], prediction of the melt flow index [10], and prediction of thermal conductivity of a polymer [11]). Compared to SVR, other approaches, such as artificial neural networks (ANN), often converge on local optima rather than on a global one. While SVM is less prone to over fitting, ANN often over fits if the training step goes on for too long.

In this paper, we investigate SVR and ANN to predict weldability in AHSS stackups. The experimental results show that SVR method outperforms ANN method since the prediction accuracy of SVR is $92 \%$ while ANN has $88.9 \%$. In addition, the effects of the parameters on nugget size are also discussed. We address quality assessment issues of resistance spot welding since quality assessment is an important step in RSW by making the welding process safer and more effective.

The remainder of this paper is organized as follows. In Section 2, we briefly review resistance spot welding and several other techniques. In Section 3, we focus on RSW and on our proposed method. The experimental design, experimental result and discussion are presented in Section 4 and Section 5. Finally, we will conclude the paper in Section 6.

\section{Related Work}

In the literature, there have been many efforts to deploy AHSS. According to A. Plath, the head of materials research and manufacturing for the Volkswagen Group, instead of using aluminum, the weld process can use advanced high strength steel, cutting one lb. of car weight with only a cost of 50 cents [14]. It costs four times less than aluminum, and he concludes that using advanced high strength steel is a very cost-effective way of reducing weight. Besides the advantages with respect to mass and cost, AHSS can reduce the carbon footprint of vehicles [15]. 
B. Acherjee et al. used a response surface method to predict the weld strength and the seam width for laser transmission welding of a thermoplastic [16]. However, the estimation of the accuracy of approximation (i.e., estimation of the magnitude of the approximation errors) is difficult. Another limitation of the method is that of local analysis. The developed response surface is invalid to use for other regions other than within the studied ranges. D. J. Radakovic and M. Tumuluru used finite element modeling and fracture mechanics calculations to predict the resistance spot weld failure mode and loads in shear-tension tests of advanced high-strength steels [17]. However, they have significant limitations for effective applications, such as high temperature material properties, multi-physical nature of RSW, and absorptive boundary conditions [18, 19].

A. G. Thakur and V. M. Nandedkar exploited an application of the Taguchi method to determine resistance spot welding conditions of austenitic stainless steel AISI 304 [20]. The Taguchi method was also used by K. S. Niranjan and Y. Vijayakumar [21] to optimize the resistance spot welding of austenitic stainless steel AISI 301L. However, the main limitation of the Taguchi method is that the results achieved are only relative and do not exactly indicate what parameter has the highest effect on the performance characteristic value. Another disadvantage is that the Taguchi methods are performed offline. Therefore, these approaches are inappropriate for a dynamically changing process such as that of a simulation study.

Darshan Shah and Dhaval P. Patel used an artificial neural network to predict weld strength in resistance spot welding [7]. A neural network is also a powerful tool for online quality assessment in RSW [3] and in the development and evaluation for industrial resistance spot welding process control and weld quality assessment [8]. R. Sohmshetty, et al. discussed the use of machine learning methods for weldability prediction of AHSS stackups and showed some results from ANN models [25]. However, other machine learning methods are not included nor compared.

G. Weber and S. Göklü introduced a process of reliability of resistance weldability for uncoated and hot dip zinc-coated high-strength TRIP steels based on multidimensional weldability lobes as well as electrode wear results for these special AHSS [22]. Several techniques are used for modeling, and the process analyses were exploited by Luo Yi, et al. in resistance spot welding on a galvanized steel sheet [23]. S. M. Hamidinejad et al. also processed analysis of resistance spot welding on galvanized steel sheets used in car body manufacturing [24].

With respect to the works mentioned, in this paper we study the use of SVR and ANN to predict nugget sizes in resistance spot welding. The experimental simulations demonstrate that the SVR provides better prediction performance, with up to $3.1 \%$ improvement over the ANN approach. We also analyzed a set of parameters in selecting appropriate parameters for the experiment of RSW. In addition, we explained and analyzed how changes in the parameters affect the nugget diameter.

\section{Welability Prediction}

\subsection{Resistance Spot Welding}

Resistance Spot Welding (RSW) is one of the most common joining methods of the electric welding process in automobile manufacturing. The weld (or nugget) is created through a combination of force, current, and time. The principle of resistance spot welding is based on the basic formula for Joule heating [26]:

$$
Q=I^{2} R t
$$


Where $Q$ is generated heat, $I$ is the current passing through the sheet metals, $R$ is the resistance of the metals and the contact interfaces, and $t$ is the time of the current flow. Figure 1 shows an example of electric resistance spot welding.

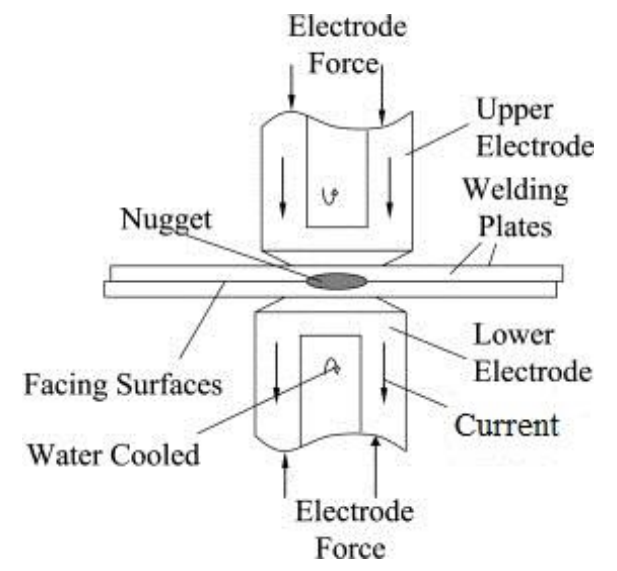

Figure 1. Electric Resistance Spot Welding [4]

RSW uses the resistance of the material that is to be welded for the current flow to cause localized heating in the part [25]. The force is created by the tongs and the electrode tips that contain the current (the current flows inside the tongs and the tips). The tongs and tips help to hold the parts to be welded in close contact throughout the welding time cycle. The welding current is an important parameter for resistance welding, which defines the heat generation by the power. In resistance spot welding, amperage values are very high and a large quantity of heat is created in a short time. Therefore, the welding time must be strictly controlled. If the welding time is prolonged, expulsion will occur and the electrode may even stick to the work piece [27]. In addition, coating is an important factor that determines the difficulty level of the welding. Uncoated steel is easier to weld when compared to coated steels.
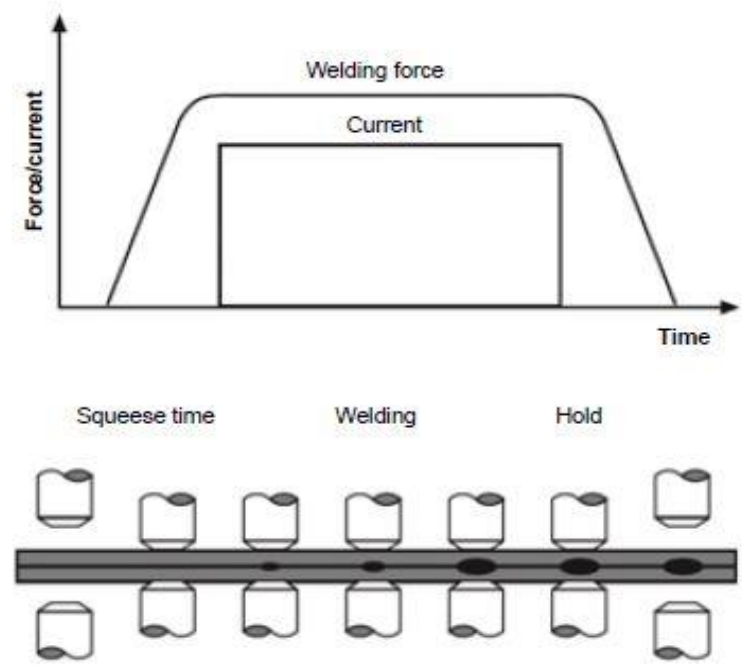

Figure 2. The Principle of Spot Welding [28]

Resistance spot welding has many advantages. First, it is an efficient process for welding, because this process does not need to use as much heat. Second, it is a simple and automatic process because RSW requires no specialized skills. Moreover, the skill of the operator does not affect the quality of the welding. Third, when compared to other 
methods, RSW generally provides a safer work environment. It does not send sparks flying, and it does not produce heavy smoke or require an open flame.

Generally, the RSW technique is used to weld metals shaped into sheets no thicker than three millimeters. Since RSW delivers a large amount of energy in a short time in order to create controlled and reliable welds, it can create an exact nugget without generating excessive heating that could affect the properties of the rest of the sheet.

As can be seen in Figure 2, the spot welding machine includes two electrodes that are positioned over the area where the bond is to be made. The two sheets of metals that are welded are clamped together by the two electrodes while an electric current is run through them. The amount of heat delivered on the spot is directly related to the resistance between the electrodes, the amplitude of the current, and the duration of the applied electric current, and that why this technique called resistance spot welding [29].

\subsection{Support Vector Regression}

Support vector machine (SVM) is a model proposed by Vladimi Vapnik and Carolina Cortes in 1995 [30]. This is a supervised learning model that is based on statistical learning theory. The main idea of SVM is to map input data into a feature vector of a higher dimension. SVM initially implements a learning algorithm to recognize patterns by mapping the nonlinearity of a complex data set into a feature space of higher dimensions. If parameters and kernel functions are appropriately chosen, SVM can be robust, even when noise exists in the data. This model can be extended to make predictions, which is then called support vector regression.

In this paper, Support Vector Regression is used to predict the weldability in resistance spot welding. With the creation of Vapnik's $\varepsilon$-insensitive loss function, a support vector machine model can be expanded to support vector regression. The weldability prediction indicates whether stack ups of a given material can be welded or not. In terms of the regression, consider a dataset $D=\left\{x_{i}, y_{i}\right\}, i=1 \ldots N$ where $x_{i}$ is a vector of a model input, $y_{i}$ is the desired result, and $N$ is the total number of data samples. The general form of the support vector regression [31] is

$$
Y_{i}=f(x)=w \varphi(x)+b
$$

Where $Y_{i}$ is the corresponding scalar output, $w$ and $b$ are the estimated coefficients, and $\varphi(x)$ is the feature vector of input $x$.

The problem with a nonlinear regression can be presented by minimizing the regularized risk function as follows:

Where

$$
R(C)=C \frac{1}{N} \sum_{i=1}^{N} L_{s}\left(d_{i} y_{i}\right)+\frac{1}{2}\|w\|^{2}
$$

$L_{s}(d, y)=\left\{\begin{array}{c}|d-y|-\varepsilon,|d-y| \geq \varepsilon \\ 0, \quad \text { others }\end{array}\right.$

$L_{s}(d, y)$ is Vapnik's $\varepsilon$-insensitive loss function that will equal to zero if $Y_{i}$ is within the $\varepsilon$-tube, $C$ is the regularization constant, $\varepsilon$ is the precision parameter presenting the distance of the tube located around regression function, $d$ is the actual value at period $i$, and $y$ is the estimation value at period $i$. Finally, $\frac{1}{2}\|w\|^{2}$ is the norm of the weight vector used to calculate the flatness of the function.

Next, we use two variables, $\xi$ and $\vec{\xi}$ to represent the distance from the point of the actual values to the boundary values. Eq. (3) can be expressed in the following constrained form: 


$$
\begin{gathered}
R(w, \xi, \hat{\xi}) \\
=\frac{1}{2}\|w\|^{2}+C \sum_{i=1}^{N}\left(\xi_{i}+\hat{\xi}_{i}\right)
\end{gathered}
$$

subject to: $\left\{\begin{array}{c}y_{i}-w \varphi\left(x_{i}\right)-b \leq \varepsilon+\xi_{i} \\ w \varphi\left(x_{i}\right)+b-y_{i} \leq \varepsilon+\hat{\xi}_{i} \\ \xi, \hat{\xi} \geq 0, i=1, \ldots, N\end{array}\right.$

In order to solve the constrained optimization problem, the Lagrangian form $\left(\alpha_{i}, \hat{\alpha}_{i}\right)$ that satisfies the equality $\alpha_{i} \times \hat{\alpha}_{i}=0$ where $\alpha_{i} \geq 0$ and $\hat{\alpha}_{i} \geq 0$ is used:

$$
\begin{aligned}
& L\left(w_{i}, \xi_{,}, \hat{\xi}_{,} \alpha_{i}, \hat{\alpha}_{i}, \beta_{i}, \hat{\beta}_{i}\right) \\
= & C \sum_{i=1}^{N}\left(\xi_{i}+\hat{\xi}_{i}\right)+\frac{1}{2}\|w\|^{2}-\sum_{i-1}^{N} \alpha_{i}\left[w_{i} \varphi\left(x_{i}\right)+b-y_{i}+\varepsilon+\xi_{i}\right] \\
- & \sum_{i=1}^{N} \hat{\alpha}_{i}\left[y_{i}-w \varphi\left(x_{i}\right)-b+\varepsilon+\hat{\xi}_{i}\right]-\sum_{i=1}^{N}\left(\beta_{i} \xi+\hat{\beta}_{i} \xi\right)
\end{aligned}
$$

Next, value of variables can be computed by exploiting Karush-Kuhn-Tucker (KKT) conditions which states that the product between dual variables and constraints has to vanish at the optimal solution.

$$
\begin{aligned}
& \alpha_{i}\left(\varepsilon+\xi_{i}-y_{i}+\left\langle w, x_{i}\right\rangle+b\right)=0 \\
& \hat{\alpha}_{i}\left(\varepsilon+\bar{\xi}_{i}+y_{i}-\left\langle w, x_{i}\right\rangle-b\right)=0 \\
& \text { And } \\
& \left(C-\alpha_{i}\right) \xi_{i}=0 \\
& \left(C-\hat{\alpha}_{i}\right) \hat{\xi}_{i}=0
\end{aligned}
$$

In here we can made some conclusion, first, only samples $\left(x_{i}, y_{i}\right)$ with corresponding $\hat{\alpha}_{i}=C$ lie outside the $\varepsilon$-insensitive tube. Secondly, $\alpha_{i} \hat{\alpha}_{i}=0$, i.e. there can never be a set of dual variables $\alpha_{i} \hat{\alpha}_{i}$ which are both simultaneously nonzero. Hence $b$ can be computed as follows:

$$
\begin{array}{ll}
b \geq y_{i}-\left\langle w, x_{i}\right\rangle-\varepsilon & \text { for } \alpha_{i}<C \\
b \leq y_{i}-\left\langle w, x_{i}\right\rangle-\varepsilon & \text { for } \alpha_{i}>0
\end{array}
$$

In order to make the regression, the dual form of the nonlinear SVR is used, and it can be expressed (after Karush-Kuhn-Tucker conditions are applied) as:

$$
\begin{aligned}
Q\left(\alpha_{i}, \hat{\alpha}_{i}\right) & =\sum_{i=1}^{N} y_{i}\left(\alpha_{i}-\hat{\alpha}_{i}\right)-\varepsilon \sum_{i=1}^{N}\left(\alpha_{i}+\hat{\alpha}_{i}\right) \\
& -\frac{1}{2} \sum_{i=1}^{N} \sum_{j=1}^{N}\left(\alpha_{i}-\hat{\alpha}_{i}\right)\left(\alpha_{j}-\hat{\alpha}_{j}\right) K\left(x_{i}, x_{j}\right)
\end{aligned}
$$

$$
\text { Subject to: }\left\{\begin{array}{c}
\sum_{i=1}^{N}\left(\alpha_{i}-\hat{\alpha}_{i}\right)=0 \\
0 \leq \alpha_{i}, \hat{\alpha}_{i} \leq C, \mathrm{i}=1,2, \ldots, N
\end{array}\right.
$$

$\alpha_{i}$ and $\hat{\alpha}_{i}$ are the Lagrange multipliers that satisfy the condition where $\alpha_{i} \times \hat{\alpha}_{i}=0$. A kernel function is used to map the data into a feature space of higher dimension. The radial basis function (RBF), one of the most common kernel functions, is used in this paper. This function can be denoted as follows:

$$
K\left(x_{i}, x_{j}\right)=\exp \left(-\frac{1}{2 \sigma^{2}}\left\|x_{i}-x_{j}\right\|^{2}\right)
$$

Where $\sigma$ is the width of the RBF and is also determined by users. 
Finally the model used for regression is formulated as follows:

$$
f(x, \alpha, \hat{\alpha})=\sum_{i=1}^{N}\left(\alpha_{i}-\hat{\alpha}_{i}\right) K\left(x_{i}, x\right)+b
$$

While $b$ is given by

$$
\begin{aligned}
\max \left\{-\varepsilon+y_{i}-\left\langle w, x_{i}\right\rangle \mid \alpha_{i}<C \text { or } \hat{\alpha}_{i}>0\right\} \leq \boldsymbol{b} \\
\leq \min \left\{-\varepsilon+y_{i}-\left\langle w, x_{i}\right\rangle \mid \alpha_{i}>0 \text { or } \hat{\alpha}_{i}<C\right\}
\end{aligned}
$$

Figure 3 shows an example of a classifier that separates a set of objects into their respective groups with a line. But most classification tasks are not that simple which is illustrated in Figure 3(b). In this case it is clear that a curve is needed to fully separate the circle and square objects. The illustration in Figure 4 shows the basic idea behind SVM kernels. The original objects are mapped or rearranged using a kernel function. The process of rearranging the objects is known as mapping or transformation. Although the transformation may be non-linear and the transformed space is high dimensional, as the result of kernels' transformation, the mapped objects are linearly separable instead of constructing the complex curve.

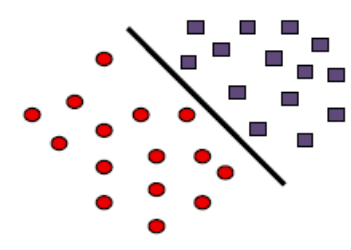

(a)

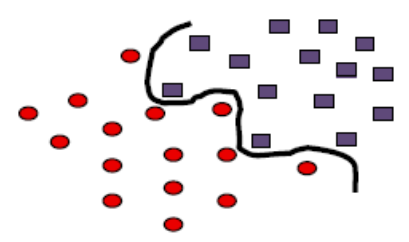

(b)

Figure 3. Linear Classifier (a) and Complicated Classified by a Curve (b) [36]

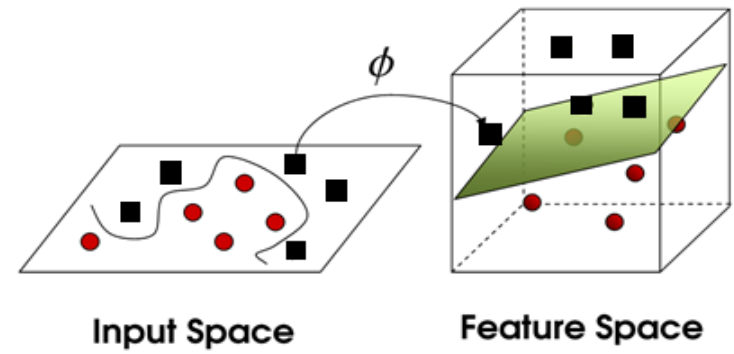

\section{Figure 4. Function of $\varphi(x)$ that Maps the Input into a Feature Space of Higher Dimension [37]}

\subsection{Artificial Neural Network}

An artificial neural network (ANN) is a computational model inspired in the natural neurons. Natural neurons receive signals though synapses located on the dendrites or membrane of the neuron. When the received signals are strong enough, the neuron is activated and emits a signal through the axon. This signal might be sent to another synapse, and might activate other neurons.

ANN has been applied in many fields such as engineering, stock prediction and health prediction- monitoring systems. ANN is a non-linear learning model that can tolerate noises. Since ANN attempts to imitate the learning activities of the human brain, it provides a means to model the input-output relationship of data in a non-linear fashion. 
Although optimality is not guaranteed, ANN has been applied to a variety of difficult-tomodel problems with various levels of success.

ANN has many advantages; this model needs less formal statistical training to develop. In addition, ANN can implicitly find complex nonlinear relationships between independent and dependent parameters make them easy to solve. A general ANN-based model is able to accurately and reliably provide an appropriate assessment of the weld quality under diverse and various welding conditions [3].

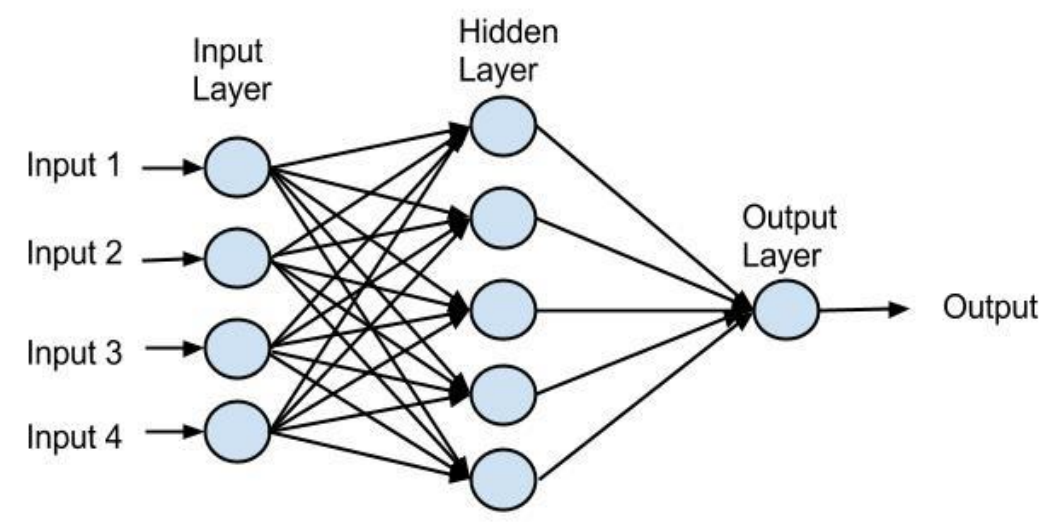

Figure 5. Layers in Artificial Neural Network

ANN is a mathematical model including an interconnected group of artificial neurons that use a connectionist approach to compute processing information. Some of the most common neural networks used are Feed-forward, Perceptron and Multi-Layer Perceptron. Neuron networks are made up of layers connected by synapses. Layers can be classified into three groups: input layer, hidden layer and output layer. The input layer sends data via synapses to the hidden layer. Hidden layers accept data from the input layer for processing. The output layer receives data from the input and hidden layer and gives results. Figure 5 shows an example of layers in ANN. Most of the algorithms used in training ANN employ a form of gradient descent. This is done by simply taking the derivative of the cost function with respect to the network parameters and then changing those parameters in a gradient-related direction.

Mathematically, the ANNs model can be written as in the following [35];

$$
y=f(x, \theta)+\varepsilon
$$

Where $\mathrm{x}$ is the vector of explanatory variables, $\theta$ is weight vector and $\varepsilon$ is the random error component. In order to estimate and predict from the available data, the unknown function can be defined as:

$$
Y=f\left[v_{0}+\sum_{i=1}^{m} h\left(\lambda_{i}+\sum_{j=1}^{n} x_{j} w_{i j}\right) v_{i}\right]
$$

Where:
$Y$ : network output
$f:$ output layer activation function
$v_{0}$ : output bias
$m$ : number of hidden units
$h$ : hidden layer activation function
$\lambda_{i}$ : hidden unit biases $(i=1, \ldots, m)$
$n$ : number of input units 


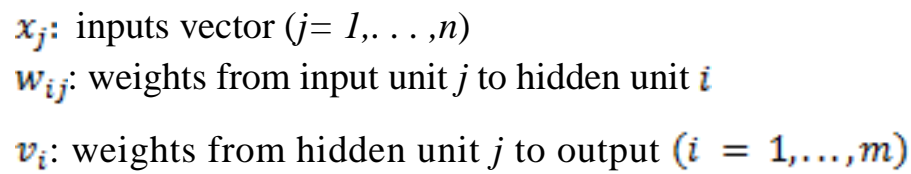

\section{Experimental Design}

In this study, the variables in RSW were classified into four types: "Design Variables," "Physical Variables," "Process Variables," and "Response Variables." The typical parameters identified within each of these variables are listed in Table 1.

Parameter selection is an important step to obtain useful results from the prediction. One of the tasks that we need to do perform during prediction of resistance spot welding system is to reduce the amount of data needed for the process. In the parameter selection stage, we need to select a subset of parameters from the initial set that can provide most of the relevant information presented in the data, and the less relevant parameters are removed.

Table 1. List of Variables Used to Identify Parameters in RSW

\begin{tabular}{|c|c|c|c|}
\hline Design Variables & Physical Variables & $\begin{array}{l}\text { Process } \\
\text { Variables }\end{array}$ & Response Variables \\
\hline $\begin{array}{l}\text { - Material Grade } \\
\text { - Thickness } \\
\text { - Coating } \\
\text { - Steel Supplier } \\
\text { - Heat Treatment } \\
\text { (Yes/No) } \\
\text { - Surface Treatment }\end{array}$ & $\begin{array}{l}\text { - Yield strength } \\
\text { - Modulus } \\
\text { - Min UTS } \\
\text { - Chemical composition } \\
\text { - Thermal composition } \\
\text { - Heat capacity } \\
\text { - Surface resistivity } \\
\text { - Bulk resistivity } \\
\text { - Surface coating } \\
\text { material } \\
\text { - Surface coating } \\
\text { thickness } \\
\text {-Carbon Equivalency }\end{array}$ & $\begin{array}{l}\text { - Weld Current } \\
\text { - Weld Force } \\
\text { - Weld Time } \\
\text { - Transformer } \\
\text { (kVA) } \\
\text { - Current type } \\
\text { - Electrode type } \\
\text { upper } \\
\text { - Electrode type } \\
\text { lower } \\
\text { - } \\
\text { polarity "+" on } \\
\text { top sheet }\end{array}$ & $\begin{array}{l}\text { - Nugget Width } \\
\text { - If Expulsion occurs } \\
\text { (Yes/No) } \\
\text { - Welding current at } \\
\text { minimum button } \\
\text { diameter } \\
\text { - Welding current at } \\
\text { expulsion } \\
\text { - Penetration into top } \\
\text { sheet } \\
\text {-Penetration } \\
\text { bottom sheet } \\
\text { - Indentation } \\
\text { - Avg. Shear tension } \\
\text { strength } \\
\text { - Avg. Cross tension } \\
\text { strength }\end{array}$ \\
\hline
\end{tabular}

According swantec.com, the three most importance parameters in resistance spot welding process are welding current, welding time, and welding force [27]. In addition, if the thickness of the materials is dissimilar, welding will be more difficult. Further, a coating cover on the material directly influences the quality of the welds and also makes the weld more difficult to perform. The nugget width is the parameter that we need to observe in this work. Therefore, in our experiment, the selected parameters to be observed are the weld current, the weld force, the weld time, thickness of the steels, whether the metal is coated, and nugget widths. The parameters are interdependent and mutually influence each other. Before the data is entered into the system, the variables are converted from design variables to nominal variables to help the system understand the meaning of these parameters.

To identify the executable working ranges of the welding conditions, several trial tests were carried out. Different combinations of RSW parameters were used during the trial runs, and nugget appearance was inspected to identify the appropriate ranges of the welding parameters. In this regard, it was observed that if the welding times were less than 12 cycles, there would be a lack of fusion and incomplete penetration. Furthermore, 
such cycles produced very small nuggets. On the other hand, if welding time is greater than 41 cycles, it is resulted in weld splash and spatter, penetration of the electrodes into the workpiece, and workpiece crushing. Also, welding currents of less than $4 \mathrm{kA}$ resulted in incomplete penetration and lack of fusion. For currents greater than $15 \mathrm{kA}$, weld splash and spatter would occur. The limits for the electrode force were determined in a similar fashion. Therefore, the adopted parameters and their given ranges are designed to avoid some abnormal results, such as weld splash and incomplete penetration. These are: weld current ranges within $4 \mathrm{kA}$ to $15 \mathrm{kA}$; weld force from $900 \mathrm{lbs}$ to $1520 \mathrm{lbs}$; welding time from 12-41 cycles, and thickness of approximately $1-3 \mathrm{~mm}$ as showed in Table 2 . The sheet metal can be coated or not.

Table 2. Experimental Variable Levels

\begin{tabular}{|c|c|c|c|c|c|}
\hline $\begin{array}{c}\text { Experimental } \\
\text { variables }\end{array}$ & & $\begin{array}{l}\text { Low } \\
\text { level }\end{array}$ & & $\begin{array}{l}\text { High } \\
\text { level }\end{array}$ & \\
\hline Force (lbs) & \multirow{3}{*}{$\begin{array}{l}\text { Lack of } \\
\text { fusion and } \\
\text { incomplete } \\
\text { penetration }\end{array}$} & 900 & 1200 & 1520 & \multirow{3}{*}{$\begin{array}{l}\text { weld } \\
\text { splash and } \\
\text { spatter }\end{array}$} \\
\hline Current (kA) & & 4 & 10 & 15 & \\
\hline $\begin{array}{l}\text { Welding Time } \\
(\text { Cycle }(1 / 50 \mathrm{~s}))\end{array}$ & & 12 & 25 & 41 & \\
\hline
\end{tabular}

\section{Comparison Results of SVR and ANN}

We conducted experiments on a dataset from an automotive OEM company. The dataset contain 784 data instances (784 row corresponding) and 10 columns of input values, including weld force, weld current, weld time, thickness, coating, and nugget size. We removed 64 instances if the nugget size was 0 (the total number of data instances was 848 ). The data is randomly partitioned into two parts with $80 \%$ of the dataset used for training and $20 \%$ of the dataset used for testing.

SVR and ANN are applied to predict nugget sizes with the selected parameters. In this experiment we tried to use polynomial as well as radial basis functions (RBF) on the same dataset for the comparison. It was found that the radial basis function offers better performance. To determine the values for the parameters, we used the grid search method [33]. The grid search is a straightforward method that uses an exponentially growing sequence of Capacity $(C)$ and Epsilon $(\varepsilon)$ in formulas (3)-(5) to identify optimum parameters. It will select the best parameters of $C$ and $\varepsilon$ with the lowest regression errors. After the trial runs with grid search method, it was found that the appropriate values of $C$ and $\varepsilon$ were 100 and 0.01 for this data set, respectively. The radial basis function is selected as a kernel type whose value of sigma $(\varepsilon)$ is 0.6. In the ANN method, the best results are from the input layer to 10 nodes, hidden layer to 10 nodes and one output node, and the activation function is the Tanh function.

Table 3. The Result of Two Methods: SVR and ANN

\begin{tabular}{|l|c|c|}
\hline $\begin{array}{l}\text { Range of welding } \\
\text { current (kA) }\end{array}$ & $\begin{array}{l}\text { Average accuracy } \\
\text { of SVR(\%) }\end{array}$ & $\begin{array}{l}\text { Average accuracy } \\
\text { of ANN (\%) }\end{array}$ \\
\hline $\begin{array}{l}4-6 \\
\text { (thickness not same) }\end{array}$ & 92.35 & 90.04 \\
\hline $\begin{array}{l}7-11 \\
\text { (normal) }\end{array}$ & $\mathbf{9 5 . 1 3}$ & 93.18 \\
\hline $\begin{array}{l}12-15 \\
\text { (coated added and } \\
\text { thickness not same) }\end{array}$ & 80.45 & 81.11 \\
\hline Average & 92 & 88.9 \\
\hline
\end{tabular}


The results of experiment were affected by setting the welding parameters. If the current is higher, the nugget size is bigger under the same thickness and weld time conditions. As illustrated in Table 3, within the range of 7-11 kA, the predicted result shows the best result compared other ranges. For the 4-6 kA range, we tried different thicknesses with two steel sheets, and the results are not good showed the accuracy is $92.35 \%$ because heat propagation on two steel sheets is different, in this case, thickness of two steels are $1.2 \mathrm{~mm}$ and $2 \mathrm{~mm}$. From $12 \mathrm{kA}$ to $15 \mathrm{kA}$, the steels are coated by hot-dip galvanizing (HDG). Typically, uncoated steel is comparatively easy to weld. When HDG coating is added, the resistance spot welding process becomes more difficult and more complex. Therefore, the prediction result is not good. Overall, the accuracy of the experiment calculated for SVR achieves $92 \%$ accuracy and ANN achieves $88.9 \%$.

\section{Table 4. Comparison Results with Kernel Functions and Active Functions}

\begin{tabular}{|l|c|}
\hline Kernel Function & $\begin{array}{l}\text { Accuracy of } \\
\text { SVR (\%) }\end{array}$ \\
\hline RBF & 92 \\
\hline Polynomial & 88.3 \\
\hline
\end{tabular}

(a) Kernel Functions in SVR

\begin{tabular}{|l|c|}
\hline Active Function & $\begin{array}{l}\text { Accuracy of } \\
\text { ANN (\%) }\end{array}$ \\
\hline Sigmoid & 87.3 \\
\hline Tanh & 88.9 \\
\hline
\end{tabular}

(b) Active Functions

We investigated capacity performance of radial basis function and polynomial as kernel functions in SVR and two active function, those are sigmoid and tanh function for ANN. Table 4 shows the results of SVR and ANN approaches with kernel functions and active functions, respectively. It is observed that RBF generates higher accuracy than Polynomial as a kerner function in SVR. For ANN, Tanh shows higher accuracy than sigmoid as an active fuction when ANN predicts the nugget sizes with the selected parameters in this data.

\section{Conclusion}

In this work we compared two best known approaches in the data mining filed to predict nugget width in resistance spot welding. The experiment results showed the better prediction ability for SVR when compared to ANN. It can be concluded that through an appropriate selection of parameters, SVR can be proposed as an alternate of neural network-based models for nugget width prediction in resistance spot welding. In future research, we are going to find the best method that improves the accuracy and has the ability to solve problems with different combinations of coating and thicknesses of the steel sheets. In addition, due to complex process of RSW, the dataset contains significant of inconsistency and anomaly problem. Hence, in future research, we are also finding more suitable solutions to deal with this problem to acquire high quality welds in RSW process.

\section{Acknowledgments}

This research was supported by the Ministry of Science, ICT \& Future Planning, Korea under the Information Technology Research Center support program (NIPA-2013-H030113-3005) supervised by the National IT Industry Promotion Agency. This work was 
supported by a National Research Foundation of Korea (NRF) grant funded by the Korean government (MEST) (2013-056480). This work is partially supported by the Ford Motor Company and the USA NSF Center for e-Design.

\section{References}

[1] Datta S., "Extraction of Knowledge from High Strength Steel Data Using Soft Computing Techniques An Overview", Statistical Analysis and Data Mining, vol. 1, (2009), pp. 329-337.

[2] Wang C., Chen J., Xia Z. C. and Ren F., "Die wear prediction by defining three-stage coefficient K for AHSS sheet metal forming process", International Journal of Advanced Manufacturing Technology, vol. 69, (2013), pp.797-803.

[3] Ouafi A. E., Bélanger R. and Méthot J. F., "Artificial neural network-based resistance spot welding quality assessment system”, Revue de Métallurgie, vol. 108, (2010), pp. 343-355.

[4] Zhao D., Wanga Y., Linb Z. and Shengb S., "An effective quality assessment method for small scale resistance spot welding based on process parameters", NDT\&E International, vol. 55, (2013), pp. 36 41.

[5] S. S. Rao, "The Finite Element Method in Engineering", 5th ed. Elsevier; (2011).

[6] R. K. Roy, "Design of Experiments Using the Taguchi Approach: 16 Steps to Product and Process Improvement", 1st ed. John Wiley \& Sons, (2001).

[7] Shah D. and Patel D. P., "Prediction of Weld Strength of Resistance Spot Welding Using Artificial Neural Network", Journal of Engineering Research and Application, (2013), pp. 1486-1491.

[8] N. Ivezic, J. D. Allen Jr. and T. Zacharia, "Neural Network-Based Resistance Spot Welding Control and Quality Prediction", Intelligent Processing and Manufacturing of Materials, vol. 2, (1999), pp. 989 994.

[9] Verplancke T., Van L. S., De Turck F., Benoit D., Hoste E. and Van M. G., "Prediction of the tacrolimus blood concentration in liver transplantation patients with support vector regression during an intensive care unit stay", Critical Care, vol. 11, (2007), pp. 471.

[10] Park T. C., Kim T. Y. and Yeo Y. K., "Prediction of the melt flow index using partial least squares and support vector regression in high-density polyethylene (HDPE) process", Korean Journal of Chemical Engineering, vol. 27, (2010), pp. 1662-8.

[11] Wang G. L., Cai C. Z., Pei J. F. and Zhu X. J., "Prediction of thermal conductivity of polymer-based composites by using support vector regression", Science China Physics, Mechanics and Astronomy, vol. 54, (2011), pp. 878-83

[12] Auria L. and Moro R. A., "Support Vector Machines (SVM) as a Technique for Solvency Analysis", DIW Berlin Discussion Paper, (2008).

[13] Pai I. F., Lin C. S., Hong W. C. and Chen C. T., "A Hybrid Support Vector Machine Regression for Exchange Rate Prediction”, Information and Management Sciences, vol. 17, (2006), pp. 19-32.

[14] "Automotive New", http://www.autonews.com/article/20130317/OEM10/130319925/new-steels-fightaluminum-to-oust-heavy-metal-from-cars, March (2013).

[15] Hall J. N., "Evolution of Advanced High Strength Steels in Automotive Applications", Great Designs Steels Seminar, http://www.autosteel.org/ (available at bit.ly/V02VL3), (2011).

[16] Acherjee B., Misra D., Bose D. and Venkadeshwaran K., "Prediction of weld strength and seam width for laser transmission welding of thermoplastic using response surface methodology", Journal Applied Soft Computing Archive, vol. 11, (2011), pp. 2548-55.

[17] Radakovic D. J. and Tumuluru M., "Predicting Resistance Spot Weld Failure Modes in Shear Tension Tests of Advanced High-Strength Automotive Steels", Welding Journal, vol. 87, (2008), pp. 96-105.

[18] Chigurupati P., Chun B. K., Bandar A. and Wu W. T., "Finite Element Modeling of Resistance Spot Welding Process", International Journal of Material Forming, vol. 3, (2010), pp. 991-994.

[19] Lodygowski T. and Sumelka W., "Limitations in application of finite element method in acoustic numerical simulation", Journal of Theoretical and Applied Mechanics, vol. 44, (2006), pp. 849-865.

[20] Thakur A. G. and Nandedkar V. M., "Application of Taguchi method to determine resistance spot welding conditions of austenitic stainless steel AISI 304", Journal of Scientific \& Industrial Research, vol. 69, (2010), pp. 680-83.

[21] Singh N. K. and Vijayakumar Y., "Application of Taguchi method for optimization of resistance spot welding of austenitic stainless steel AISI 301L", Innovative Systems Design and Engineering, vol. 3, (2012), pp. 49-61.

[22] Weber G. and Göklü S., "Resistance Spot Welding of Uncoated and Zinc Coated Advanced HighStrength Steels (AHSS) - Weldability and Process Reliability-Influence of Welding Parameters", Welding in the World, vol. 50, (2006), pp. 3-12.

[23] Yi L., Jinhe L., Huibin X., Chengzhi X. and Lin L., "Regression modeling and process analysis of resistance spot welding on galvanized steel sheet", Materials \& Design, vol. 30, (2009), pp. 2547-55.

[24] Hamidinejad S. M., Kolahan F. and Kokabi A. H., "The modeling and process analysis of resistance spot welding on galvanized steel sheets used in car body manufacturing", Materials \& Design, vol. 34, (2012), pp. 759-767. 
[25] Sohmshetty R., Ramachandra R., Coon T., Choi K. and Kim K. Y., "Weldability Prediction of AHSS Stackups Using Artificial Neural Network Models", SAE Technical Paper 2012-01-0529, (2012).

[26] Zhang H. Y. and Senkara J., "Resistance Welding: Fundamentals and Applications", 2nd ed. CRC Press; (2011).

[27] "Swantec Software and Engineering ApS", http://www.swantec.com/parameters-in-resistancewelding.php, (2005).

[28] "Ruukki Resistance welding manual", http://www.ruukki.com/ /media/Files/Steel-products/Cold-rolledmetal-colour-coated-instructions/Ruukki-Resistance-welding-manual.ashx, (2009).

[29] "How Spot Welding Works", http://news.softpedia.com/news/How-Spot-Welding-Works-91337.shtml , August, (2008).

[30] Cortes C. and Vapnik V., "Support Vector Networks", Machine Learning, vol. 20, (1995), pp. 273-297.

[31] Radhika Y. and Shashi M., "Atmospheric Temperature Prediction using Support Vector Machines", International Journal of Computer Theory and Engineering, vol. 1, (2009), pp. 1793-8201.

[32] Cristianini N. and Taylor J. S., "An Introduction to Support Vector Machines and Other Kernel-based Learning Methods", Cambridge University Press, (2000), pp. 35.

[33] Hsu C. W., Chang C. C. and Lin C. J., "A practical guide to support vector classification”, Technical report, Department of Computer science and information Engineering, National Taiwan University, (2010).

[34] Yu P. S., Chen S. T. and Chang I. F., "Support vector regression for real-time flood stage forecasting", Journal of Hydrology, vol. 328, (2006), pp. 704- 716.

[35] A. Krenker, J. Bešter and A. Kos, "Introduction to the Artificial Neural Networks, Artificial Neural Networks - Methodological Advances and Biomedical Applications”, Prof. Kenji Suzuki (Ed.), ISBN: 978-953-307-243-2, InTech, DOI: 10.5772/15751, (2011).

[36] Deisy C., Gowri M., Baskar S., Kalaiarasi S. M. A and Ramraj N., "A Novel Term Weighting Scheme MIDF for Text Categorization", Journal of Engineering Science and Technology, vol. 1, (2010), pp. 94107.

[37] Shrivastava N. K., Saurabh P. and Verma B., "An Efficient Approach Parallel Support Vector Machine for Classification of Diabetes Dataset”, International Journal of Computer Applications, vol. 36, (2011), pp. 19-24.

\section{Authors}

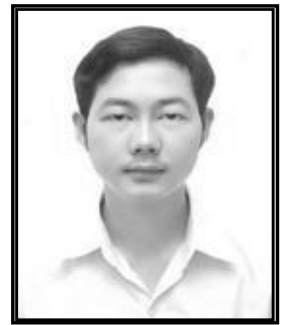

Huu Tan Tran, he received the B.S, in School of Applied Mathematics \& Informatics from Hanoi University of Science and Technology, Viet Nam in 2012. He is currently a M.S. student at Dept. of Electronics and Computer Engineering, Chonnam National University, Korea. His research interests include pattern recognitions, bioinformatics, data mining and machine learning.

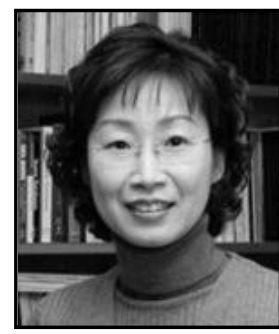

Hyung Jeong Yang, she is currently an associate professor at Dept. of Electronics and Computer Engineering, Chonnam National University, Gwangju, Korea. Her main research interests include multimedia datamining, pattern recognition, artificial intelligence, eLearning, and e-Design. 


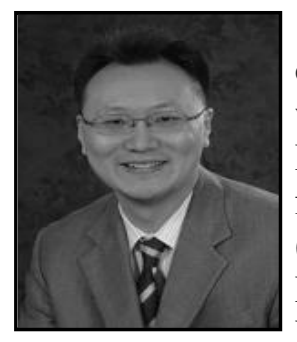

Kyung Yun Kim, he is an associate professor in the Department of Industrial and Systems Engineering at Wayne State University, where he directs the Computational Intelligence and Design Informatics (CInDI) Laboratory. Currently, Dr. Kim is a Site Director for the NSF Industry and University Cooperative Research Center (I/UCRC) for e-Design. Kim's research focuses on Design Science; Design Informatics; Semantic Assembly Design; Transformative Product Design; Product Life-cycle Modeling; Design and Manufacturing of Soft Products. Dr. Kim's education includes a B.S.

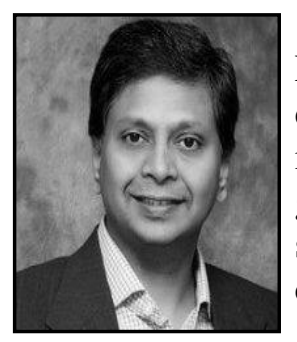

Raj Sohmshetty, He is a Group Leader at Research \& Advanced Engineering, Ford Motor Company. In this capacity, he works on development and implementation of new materials and manufacturing process technologies. Raj holds undergraduate and graduate degrees in Mechanical Engineering and an MBA. During his spare time, Raj enjoys long distance running, reading, and playing chess and poker. 